Paraquat has been described as a 'hit and run' poison (Barnes, 1968), but in view of recent reports of the apparent value of forced diuresis, the severity of pulmonary fibrosis and the prognosis in paraquat poisoning would appear to depend not only on the quantity ingested but also on the rate of removal. This case shows that even when a delay occurs before the patient is seen that the outcome of poisoning with $20 \%$ paraquat is not inevitably fatal.

\section{Acknowledgements}

We wish to thank Dr P. D. Bewsher for permission to report this case and all the staff who contributed to the care of the patient. We also wish to thank Dr D. M. Ferguson (ICI Ltd) for his advice and co-operation.

\section{References}

Barnes, J.M. (1968) Poisons that hit and run. New Scientist, 38, 619.

Fennelly, J.J., Fitzgerald, M.X. \& Fitzgerald, O. (1971) Recovery from severe paraquat poisoning following forced diuresis and immunosuppressive therapy. Journal of the Irish Medical Association, 64, 69.

Ferguson, D.M. \& Litchfield, M. (1971) Personal communiation.

Flenley, D.C. (1971) Paraquat poisoning. Clinical Pathological Conference. Scottish Medical Journal, 16, 407.

Grabensee, B., Veltmann, G., Mürtz, R. \& Borchard, F. (1971) Paraquat poisoning. Deutsche Medizinische Wochenschrift, 96, 498.

Grundies, H., Kolmar, D. \& BenNhold, I. (1971) Paraquat poisoning. Deutsche Medizinische Wochenschrift, 96, 588.

Malone, J.D.G., Carmody, M., Keogh, B. \& O'DWyer, W.F. (1971) Paraquat poisoning-A review of nineteen cases. Journal of the Irish Medical Association, 64, 59.

WeIDENBaCH, J. (1969) Paraquat poisoning. Deutsche Medizinische Wochenschrift, 94, 547.

\title{
Primary haemorrhagic thrombocythaemia with Philadelphia chromosome
}

\author{
M. L. GHOSH \\ M.B.B.S., D.T.M.\&H., D.C.H., M.R.C.P.(I), M.R.C.P.,(G) \\ Barnsley District General Hospital, Barnsley, Yorkshire
}

\begin{abstract}
Summary
A case of primary haemorrhagic thrombocythaemia with the $\mathbf{P h}^{1}$ chromosome is described and its relation with myeloproliferative disorders is discussed.

Persistent and marked increase of platelet count may be assocaited with polycythaemia vera, agnogenic myeloid metaplasia (Linman \& Bethell, 1957), chronic myeloid leukaemia (Minot \& Buckman, 1925), after splenectomy (Hardisty \& Wolff 1955), and sometimes with no obvious cause (Ozer et al., 1960 ), called primary haemorrhagic thrombocythaemia.

The Philadelphia $\left(\mathrm{Ph}^{1}\right)$ chromosome was discovered by Nowell \& Hungerford (1960) in patients with chronic granulocytic leukaemia. Since then the $\mathbf{P h}^{\mathbf{1}}$ chromosome has been demonstrated in patients who initially presented as polycythaemia, in eosinophilic leukaemia (Gruenwald et al., 1965) and in primary haemorrhagic thrombocythaemia (Tough et al., 1963; Dougan, Woodliff \& Onesti, 1967).
\end{abstract}

I present here a further case of primary haemorrhagic thrombocythaemia with the $\mathrm{Ph}^{1}$ chromosome.

\section{Case report}

A thinly-built married female aged 75 years was admitted to hospital in May 1970 for pain in the upper abdomen, particularly in left hypochondrium, bruises on the legs, a history of haematemesis, moderate anaemia and weight loss. The liver and spleen were not palpable but there was some tenderness in the splenic region. There was a past history of similar recurrent attacks of abdominal pain mainly in the splenic region and repeated gastro-intestinal haemorrhage for many years.

Investigations in a different hospital in 1959 revealed hypochromic anaemia with haemoglobin $10.5 \mathrm{~g} / 100 \mathrm{ml}$, and normal white cell count, but a platelet count was not performed. Various biochemical investigations and radiological investigations including barium studies of the gastrointestinal tract at that time did not reveal any 
abnormality. Barium studies were repeated in April 1969, and again in May 1970, for her repeated abdominal pain and gastro-intestinal tract bleeding but again no organic lesion was found.

\section{Investigations}

Hess test was negative, haemoglobin $8 \mathrm{~g} / 100 \mathrm{ml}$, WCC $9000 / \mathrm{mm}^{3}$, normal differential count, no immature cell seen. RBC 4.95 million $/ \mathrm{mm}^{3}$. Blood film showed hypochromic red cells and many platelet clumps and giant bizarre platelets, and fragments of megakaryocytes (Fig. 1) and Howell Jolly bodies. PCV $36 \%$. Platelet count on repeated occasions ranged between 1.2 and $1.8 \mathrm{million} / \mathrm{mm}^{3}$. LAP score 45. Sternal marrow showed normal cellularity with extreme increase of mature and immature megakaryocytes with sheets of platelets. The white cell precursors were normal except for an apparent increase of myeloblasts (approx. $6 \%$ of total nucleated cells). Bone marrow section stained with $H$ \& $E$ and reticulin showed megakaryocytic hyperplasia (Fig. 2) and no increase of reticulin fibre or fibrous tissue to favour the diagnosis of myelofibrosis. Bleeding time (Duke)-5 min. Clotting time (Lee \& White) -4 min. Prothrombin time (Quick)-normal. Clot retraction test was within normal limits. Thromboplastin-generation test was impaired. Chromosome study was done by 'direct' marrow technique based on modification of the method of Tjio \& Whang (1962) showed the majority of the scorable cells where the $\mathrm{Ph}^{1}$ positive (Fig. 3). Treatment with busulphan was considered but she died suddenly in June, 1970, after massive gastro-intestinal haemorrhage. Unfortunately necropsy was not possible.

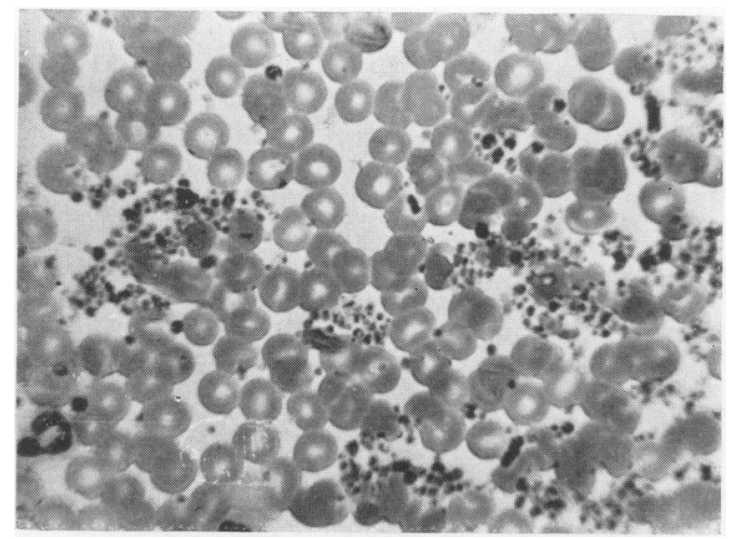

FIG. 1. Peripheral blood film showing clumps of platelets. Many are giant and bizarre forms, with fragments of megakaryocytes. $\times 275$.

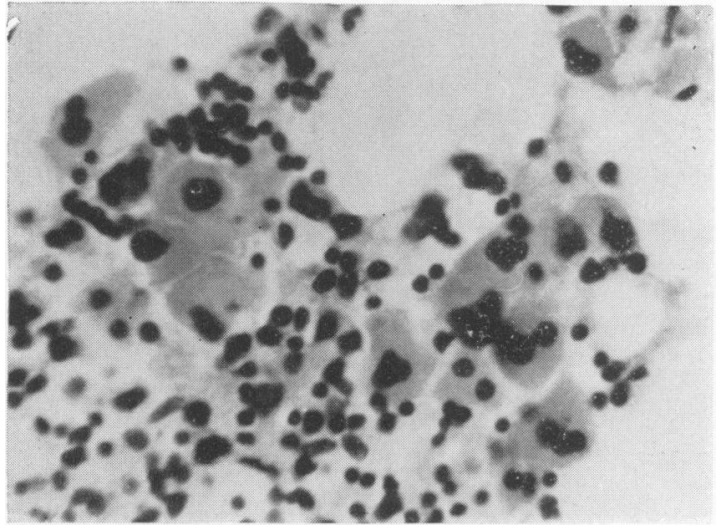

FIG. 2. Bone marrow biopsy stained with $\mathrm{H} \& \mathrm{E}$, showing megakaryocytic hyperplasia. $\times 120$.

\section{Discussion}

Haemorrhagic thrombocythaemia commonly presents with recurrent episodes of haemorrhage particularly epistaxis and gastro-intestinal bleeding and vascular thrombosis, less commonly haematuria (Hardisty \& Wolff 1965).

The exact cause of haemorrhage is not clear though there is an abnormal bleeding time in some cases, Reid (1940), or an abnormal thromboplastin-generation test (Hardisty \& Wolff, 1955) as in the present case. The spleen probably plays some part in causing haemorrhage and vascular thrombosis as splenectomy causes a further rise of platelets. In this present case the bleeding episodes were not massive until recently which could be explained if the repeated abdominal pain was due to repeated splenic thromboses and infarcts, causing splenic atrophy suggested by presence of Howell Jolly bodies and leading to further increase of platelets.

It is suggested that haemorrhagic thrombocythaemia is an atypical myeloproliferative disorder, mainly affecting the platelets, the other blood cells being near normal; the myeloid series in the bone marrow is not typical of chronic myeloid leukaemia and many such cases survive between 6 and 29 years. On the other hand, the average survival in chronic myeloid leukaemia is between 3 and 4 years and the thrombocythaemia is one aspect of the leukaemia or myelofibrosis; the prognosis depends on the state of the bone marrow.

Patients with primary thrombocythaemia, polycythaemia vera, chronic myeloid leukaemia and myelofibrosis can progress from one condition to another during the course of the disease and are regarded as varieties of myeloproliferative disorders, the basic defect being in the stem cell (Dameshek, 


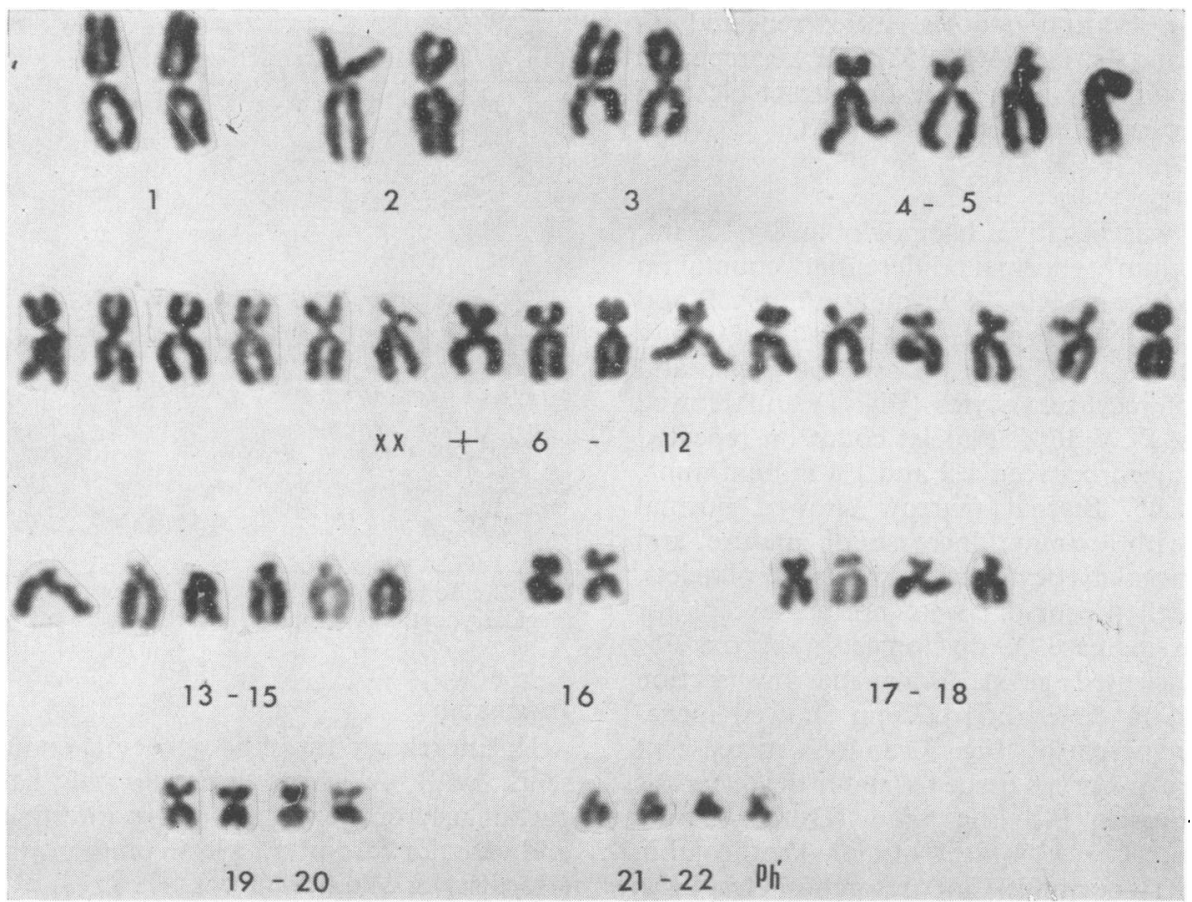

FIG. 3. Karyotype of a bone marrow cell of the patient showing Philadelphia chromosome.

1951). The $\mathrm{Ph}^{1}$ chromosome is almost always present in chronic granulocytic leukaemia when direct bone marrow preparations are used rather than peripheral blood culture (Speed \& Lawler, 1964). The findings of the $\mathrm{Ph}^{1}$ chromosomes in the bone marrow cells of patients with haemorrhagic thrombocythaemia (Tough et al., 1963; Dougan et al., $1967)$ and in this present case lend strong support for the unitarian concept of myeloproliferative disorders.

Tough et al. (1963) also noticed a large number of the $\mathbf{P h}^{1}$-positive polyploid cells in the direct marrow preparation which they considered to be megakaryocytes. They suggested that both erythroid and granulocytic cells and megakaryocytes are $\mathbf{P h}^{\mathbf{1}}$ positive and that these cell lines are derived from a common precursor cell; the $\mathrm{Ph}^{\mathbf{1}}$ chromosome is thought to originate from such a cell or cells.

Thus, there is strong evidence that this present case is an example of atypical myeloproliferative disorder in which the megakaryocytic element is predominantly affected giving rise to uncontrolled platelet production without much affecting the myeloid and erythroid lines.

\section{Acknowledgment}

I wish to thank Miss P. Cook for chromosome preparation, at the Centre for Human Genetics, The University of Sheffield.

\section{References}

DAMESHEK, W. (1951) Some speculations on the myeloproliferative syndromes. Blood, $6,372$.

Dougan, L., Woodliff, H. J. \& Onesti, P. (1967) Cytogenetic studies in megakaryocytic myelosis. Medical Journal of Australia, 1, 62.

Gruenwald, H., Kiossoglou, K.A., Mitus, W.J. \& DameSHEK, W. (1965) Philadelphia chromosome in eosinophilic leukaemia. American Journal of Medicine, 39, 1003.

HARDISTY, R.M. \& WolFF, H.H. (1955) Haemorrhagic thrombocythaemia: 'a clinical and laboratory study'. British Journal of Haematology, 1, 390.

Linman, J.W. \& Bethell, F.H. (1957) Agnogenic myeloid metaplasia. American Journal of Medicine, 22, 107.

Minot, G.R. \& Buckman, T.E. (1925) Blood platelets in the leukaemias. American Journal of Medical Science, 169, 477.

Nowell, P.C., \& Hungerford, D.A. (1960) A minute chromosome in human chronic granulocytic leukaemia. Science, 132, 1497.

Ozer, F.L., TruaX, W.E., Miesch, D.C. \& Levin, W.C. (1960) Primary haemorrhagic thrombocythaemia. American Journal of Medicine, 28, 807.

ReID, J. (1940) Haemorrhagic thrombocythaemia. Lancet, ii, 584.

SPEED, D.E. \& LAwler, S.D. (1964) Chromic granulocytic leukaemia, 'the chromosomes and the disease'. Lancet, $i$, 403,

Tü, J.H. \& Whang, J. (1962) Chromosome preparations of bone marrow cells without prior in vitro culture or in vivo colchicine administration. Stain Technology, 37, 17.

Tough, I.M., Jacobs, P.A., Court Brown, W.M., Baikie, A.G. \& Williamson, E.R.D. (1963) Cytogenetic study on bone marrow in chronic myeloid leukaemia. Lancet, i, 844. 